\title{
Memory Intervention
}

National Cancer Institute

\section{Source}

National Cancer Institute. Memory Intervention. NCI Thesaurus. Code C116526.

Any action taken for the purpose of improving an individual's memory. 